\title{
Rancang Bangun Aplikasi Inventory Material Jasa Pelaksana Kontruksi PT. Bawan Permai Group Berbasis Website
}

\author{
Veni Laola ${ }^{1}$, Widiatry ${ }^{2 *}$, Licantik $^{3)}$ \\ 1)23) Jurusan Teknik Informatika, Fakultas Teknik, Universitas Palangka Raya \\ Jalan Hendrik Timang Kampus Tunjung Nyaho, Palangka Raya \\ *corresponding author \\ 1) venii.laola@gmail.com \\ ${ }^{2)}$ widiatry@it.upr.ac.id \\ 3) licantikmeteh@gmail.com
}

\begin{abstract}
Abstrak
PT. Bawan Permai Group ini merupakan perusahaan yang bergerak di bidang pengadaan jasa kontruksi (pemborong). Maka dibuat sebuah sistem terkomputerisasi bertujuan sebagai media yang memfasilitasi dan membantu pihak perusahaan dalam mengelola, mendata ataupun mengontrol inventory (persediaan) material jasa pelaksana kontruksi. Metodologi yang digunakan dalam pembuatan aplikasi ini, yaitu Waterfall Menurut Summerville tahun 2011, yang memiliki tahapan yaitu Requirements Definition yang dilakukan dengan pembuatan Flowchart sistem lama dan sistem baru. System and Software Design dilakukan pembuatan Data Flow Diagram (DFD) dan Entity Relationship Diagram (ERD). Implementation and Unit Testing dilakukan realisasi sistem pada tahap sebelumnya ke dalam bahasa pemrograman PHP dan basis data MySQL. Integration and System Testing dilakukan pengujian kembali dengan menggunakan Blackbox Testing. Blackbox Testing fokus pada spesifikasi fungsional dari program. Setelah melakukan testing, dapat dilihat hasilnya, yaitu sistem dapat berjalan dengan baik. Walaupun demikian, aplikasi ini harus selalu dipantau, dikembangkan dan diperbaharui agar informasi dapat tersampaikan dengan baik dan sesuai dengan kebutuhan pengguna.
\end{abstract}

Kata kunci: Inventory, Website, Waterfall, Terkomputerisasi.

\begin{abstract}
PT. Bawan Permai Group is a company engaged in the procurement of construction services (contractor). So a computerized system is created which aims as a medium that facilitates and assists the company in managing, recording or controlling the inventory of construction services materials. The methodology used in making this application, namely Waterfall According to Summerville in 2011, which has stages, namely Requirements Definition which is carried out by making Flowcharts of the old system and the new system. System and Software Design is made by making Data Flow Diagrams (DFD) and Entity Relationship Diagrams (ERD). Implementation and Unit Testing is carried out by the realization of the system in the previous stage into the PHP programming language and MYSQL database.Integration and System Testing is retested using Blackbox Testing. Blackbox Testing focuses on the functional specifications of the program. After testing, the results can be seen, namely the system can run properly. However, this application must always be monitored, developed and updated so that information can be conveyed properly and according to user needs.
\end{abstract}

Keywords: Inventory, Website, Waterfall, Computerized. 


\section{PENDAHULUAN}

Perkembangan teknologi yang cukup pesat dari waktu ke waktu membuat pekerjaan yang dilakukan manusia pada umumnya dapat diselesaikan dengan cepat. Teknologi merupakan salah satu alat bantu yang sering digunakan dalam aktivitas manusia dengan menerapkan dasar pemrograman website dinamis menggunakan php [1]. Peran serta teknologi menjadikan pengolahan informasi menjadi semakin mudah karena pengolahan sangat diperlukan agar informasi yang dihasilkan dapat bermanfaat bagi penggunanya. Pengolahan data dan informasi secara tepat dan efisien adalah hal penting yang dibutuhkan bagi setiap perusahaan atau suatu instansi untuk meningkatkan produktifitas pekerjaan [2]. Seiring berkembangnya kemajuan teknologi informasi dan komunikasi, persaingan bisnis dalam dunia jasa pelaksanaan kontruksi semakin ketat. Jumlah perusahaan semakin banyak dan terus melakukan usaha dan strategi dalam mempertahankan bisnisnya, maka perlu dilakukan sebuah analisis dan perancangan [3].

Kesuksesan perusahaan dalam mempertahankan bisnisnya tidak terlepas dari peran perusahaan tersebut dalam mengelola website profil hingga inventory (persediaan) material jasa pelaksana kontruksi sehingga dapat memenuhi permintaan pelanggan dan tentu saja dapat menjaga kelangsungan bisnisnya dalam dunia pelaksanaan jasa kontruksi saat ini [4]. Inventory didalam suatu usaha menjadi hal yang penting bagi suatu perusahaan, karena dari inventory tersebut bisa mengelola persediaan material-material untuk kebutuhan dalam melakukan pelaksanaan kontruksi [5]. Penerapan teknologi pada PT. Bawan Permai Group saat ini masih dikatakan kurang. Semua proses pembukuan inventory (persediaan) dan laporan keluar masuknya material-material jasa pelaksana kontruksi masih dilakukan dengan menggunakan cara manual dengan cara mencatat pada form di kertas dan kemudian di salin di buku besar [6]. Atas dasar tersebut maka untuk meningkatkan produktifitas pekerjaan, waktu, biaya dan daya saing PT. Bawan Permai Group maka penulis tertarik dan berminat untuk membuat sistem informasi inventory (persediaan) [7].

Beberapa penelitian yang digunakan untuk menambah pengetahuan dalam mengembangkan aplikasi berbasis website dan desktop adalah Rancang Bangun Aplikasi Inventory Sayuran Berbasis Desktop di Perusahaan CV. Garut Power [8]. Sistem Informasi Inventory Control Pada Perusahaan Industri Gas di PT. XYZ [9]. Rancang Bangun Website untuk Memeriksa Plagiat EJournal Fakultas Kedokteran Universitas Palangka Raya [10] dan Sistem Pendukung Keputusan untuk Seleksi Penerima Beasiswa BBP-PPA dengan Metode TOPSIS berbasis Web [11].

\section{TINJAUAN PUSTAKA}

Adapun beberapa penelitian yang sudah dilakukan sebelumnya, antara lain sebagai berikut :

a. Abi Abdurahim dan Leni Fitriani (2016) jurnal ini berjudul "Rancang Bangun Aplikasi Inventory Sayuran Berbasis Desktop di Perusahaan CV. Garut Power". Penelitian ini bertujuan untuk membuat sebuah aplikasi inventory sayuran, dimana aplikasi tersebut diharapkan dapat membantu kinerja, memantau distribusi sayuran serta keberadaan stok secara pasti kapanpun diinginkan pada Perusahaan Garut Power.

b. Arizal dan Anita Qoiriah (2014) jurnal ini berjudul "Sistem Informasi Inventory Control Pada Perusahaan Industri Gas di PT. XYZ". Penelitian ini bertujuan untuk memeperluas jaringan pemasaran dan meningkatkan daya saing memberi pelayanan dan solusi bagi para pelanggannya. Sistem ini memiliki fasilitas untuk mencetak data-data, seperti form keluar, form kembali, form masuk, form retur, dan juga laporan-laporan yang dibutuhkan bagi perusahaan yaitu laporan berdasarkan periode tertentu dan juga stock opname. Laporanlaporan ini nantinya dapat digunakan untuk peningkatkan kualitas layanan maupun meminimalisasi kesalahan-kesalahan yang mampu merugikan perusahaan maupun pelanggan.

c. Beberapa penelitian mengenai sistem informasi inventory yang telah dilaksankan oleh peneliti sebelumnya. Maka perbedaan yang dimiliki yang diusulkan penulis yaitu "Rancang Bangun Aplikasi Inventory Material Jasa Pelaksana Kontruksi PT.Bawan Permai Group 
berbasis Website" yang menggunakan metode pengembangan perangkat lunak waterfall model dan pada website ini memiliki fitur safety stock dimana fitur ini berfungsi untuk mengelola persediaan tambahan yang diadakan untuk melindungi atau menjaga kemungkinan terjadinya kekurangan persediaan.

\section{METODE PENELITIAN}

\subsection{Studi Pendahuluan}

\section{A. Lokasi Penelitian}

Penelitian ini berlokasi di Jalan Rajawali VII No. 38. Kel. Bukit Tunggal, Kec. Jekan Raya, Kota Palangka Raya.

B. Alat dan Bahan

1. Hardware : Laptop ASUS A407U, Processor : Intel@ Core TM i7-8550U CPU @ $1.80 \mathrm{GHz} 1.99 \mathrm{GHz}$, RAM : 8,00 GB (7,88 GB usable), Harddisk : $1 \mathrm{~TB}$, NVIDIA® GeForce ${ }^{\circledR}$.

2. Software : Sistem Operasi, yaitu Windows 10, 64-bit, Database Editor, yaitu SQLyog 11, Desain Database, yaitu Edraw Max 7, Desain Grafis, yaitu Adobe Photoshop CS6, Text Editor, yaitu Sublime text, Adobe DW CS6, Web Server, yaitu XAMPP 1.7.7, Browser, yiatu Mozilla Firefox.

\subsection{Metode Pelaksana}

a. Metode Pengumpulan Data

Tahap pengambilan data yang berkaitan dengan permasalahan yang di bahas. Metode ini menggunakan teknik wawancara, yakni menanyakan langsung kepada pihak PT. Bawan Permai Group. Data-data yang dikumpulkan berupa prosedurprosedur yang diterapkan dan standar yang digunakan.

b. Metode Studi Kepustakaan

Mempelajari informasi dari internet maupun jurnal-jurnal yang memiliki kaitan dengan proses pembuatan sistem ini dan memilah kembali fitur-fitur apa saja yang cocok untuk diterapkan dalam website.

c. Metode Konsultasi dan Perancangan Sistem

Metode konsultasi dan Perancangan Sistem merupakan proses tanya jawab atau bimbingan dan diskusi kepada dosen pembimbing mengenai website yang di buat sehingga ditemukan arah seperti apa website nantinya.

d. Metode Implementasi

Metode ini dimana mulai melakukan proses pengerjaan website dengan data yang sudah dikumpulkan dan dirancang sedemikian rupa.

\subsection{Metode Pengembangan Sistem}

Metode pengembangan sistem yang digunakan dalam sistem ini menggunakan model pengembangan waterfall menurut Ian Sommerville (2011).

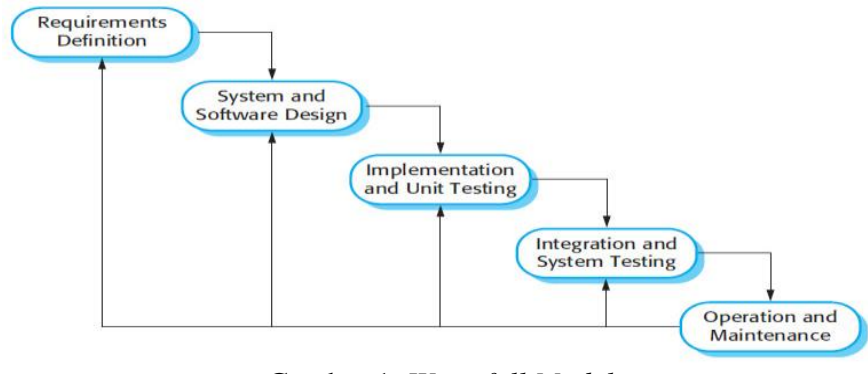

1. Requirements Definition

Gambar 1. Waterfall Model 
Pada tahap ini penulis melakukan analisis sistem yang sedang berjalan, melakukan wawancara langsung kepada pihak perusahaan mengenai permasalahan yang ada, merancang batasan sistem serta kebutuhan yang diperlukan untuk pembuatan sistem. Kemudian penulis memberikan sistem usulan dari masalah yang ada untuk dibuatkan sistem yang baru.

2. System and Software Design

Dari usulan sistem yang baru, pada tahap ini penulis melakukan perancangan sistem mulai dari desain sistem menggunakan DFD dan ERD [12], desain interface hingga desain database berdasarkan hasil analisis pada tahap sebelumnya hingga menjadi suatu arsitektur sistem berdasarkan persyaratan yang telah disepakati dengan pihak perusahaan.

3. Implementation and Unit Testing

Pada tahap ini penulis merealisasikan rancangan sistem pada tahap sebelumnya ke dalam bahasa pemrograman PHP dan basis data MySQL menjadi suatu unit program. Kemudian unit program yang telah dibuat tadi dilakukan pengujian untuk mengetahui apakah program sudah berjalan sesuai dengan yang diharapkan penulis [13].

4. Integration and System Testing

Setelah pengujian unit program, pada tahap ini penulis melakukan pengujian kembali terhadap tiap-tiap unit program menjadi satu kesatuan program hingga sesuai dengan yang diharapkan. Penulis melakukan pengujian menggunakan jenis pengujian blackbox [14].

\section{Operation and Maintenance}

Setelah sistem selesai diuji dan kemudian diberikan ke pengguna sistem (dalam hal ini pengguna sistem adalah pihak perusahaan), pada tahap ini pihak perusahaan mulai mengoperasikan sistem. Sehingga penulis hanya melakukan hingga tahap Integration and System Testing saja. Namun dalam kurun waktu tertentu, sistem akan dievaluasi kembali untuk dilakukan pengembangan sistem seperti penambahan fitur dan fungsi baru, maupun memperbaiki error yang tidak ditemukan pada saat pembuatan ataupun pengujian sistem.

\section{PEMBAHASAN}

\subsection{Perancangan Sistem}

\section{Requirement Definition}

Tabel 1. Flowchart Sistem Lama

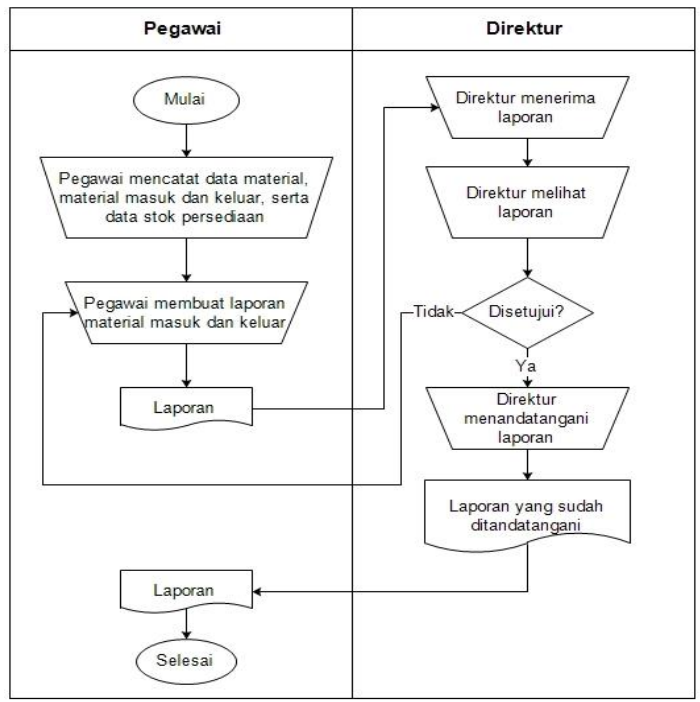

Tabel 2. Flowchart Sistem Baru Admin 


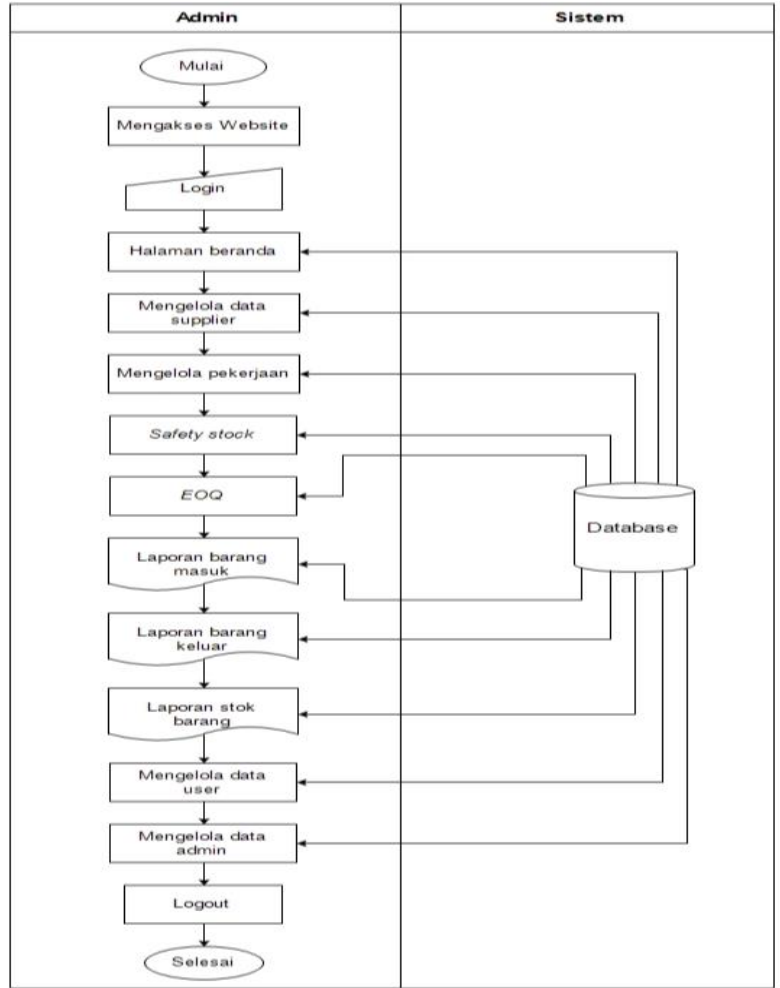

Tabel 3. Flowchart Sistem Baru Direktur

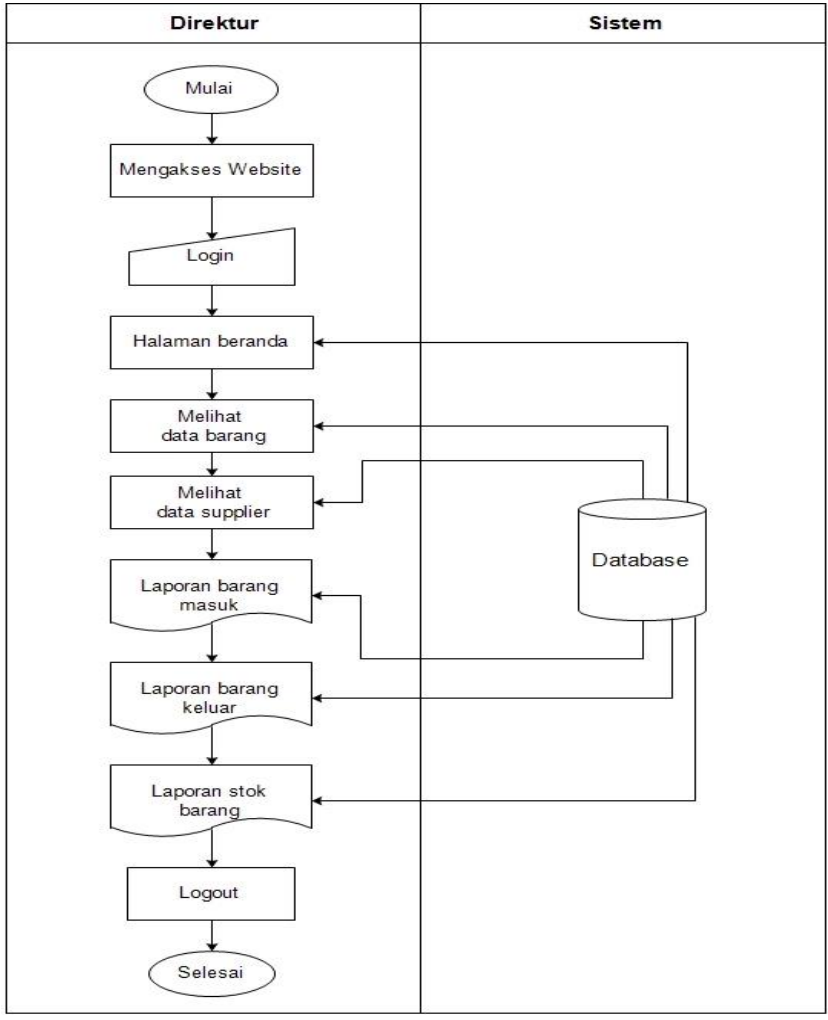


Tabel 4. Flowchat Sistem Baru Gudang

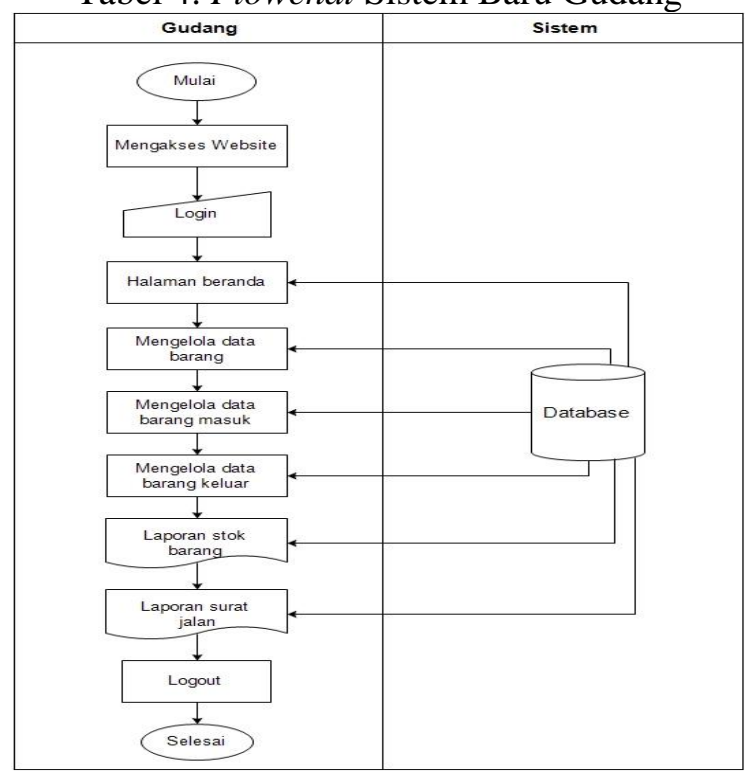

2. System and Software Design

b. Data Flow Diagram (DFD) Level 1

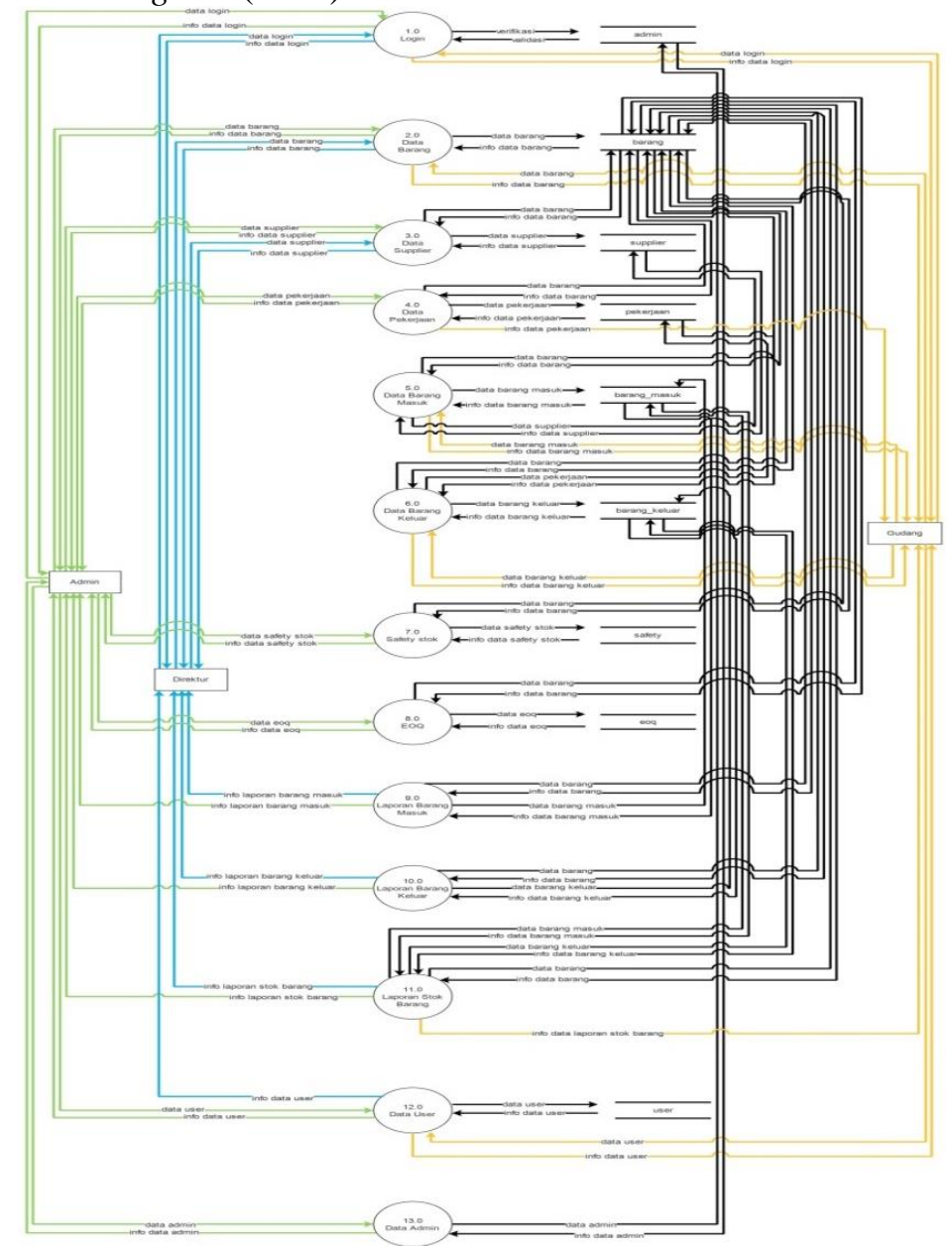

Gambar 3. DFD Level 1

c. Entity Relationship Diagram (ERD) 


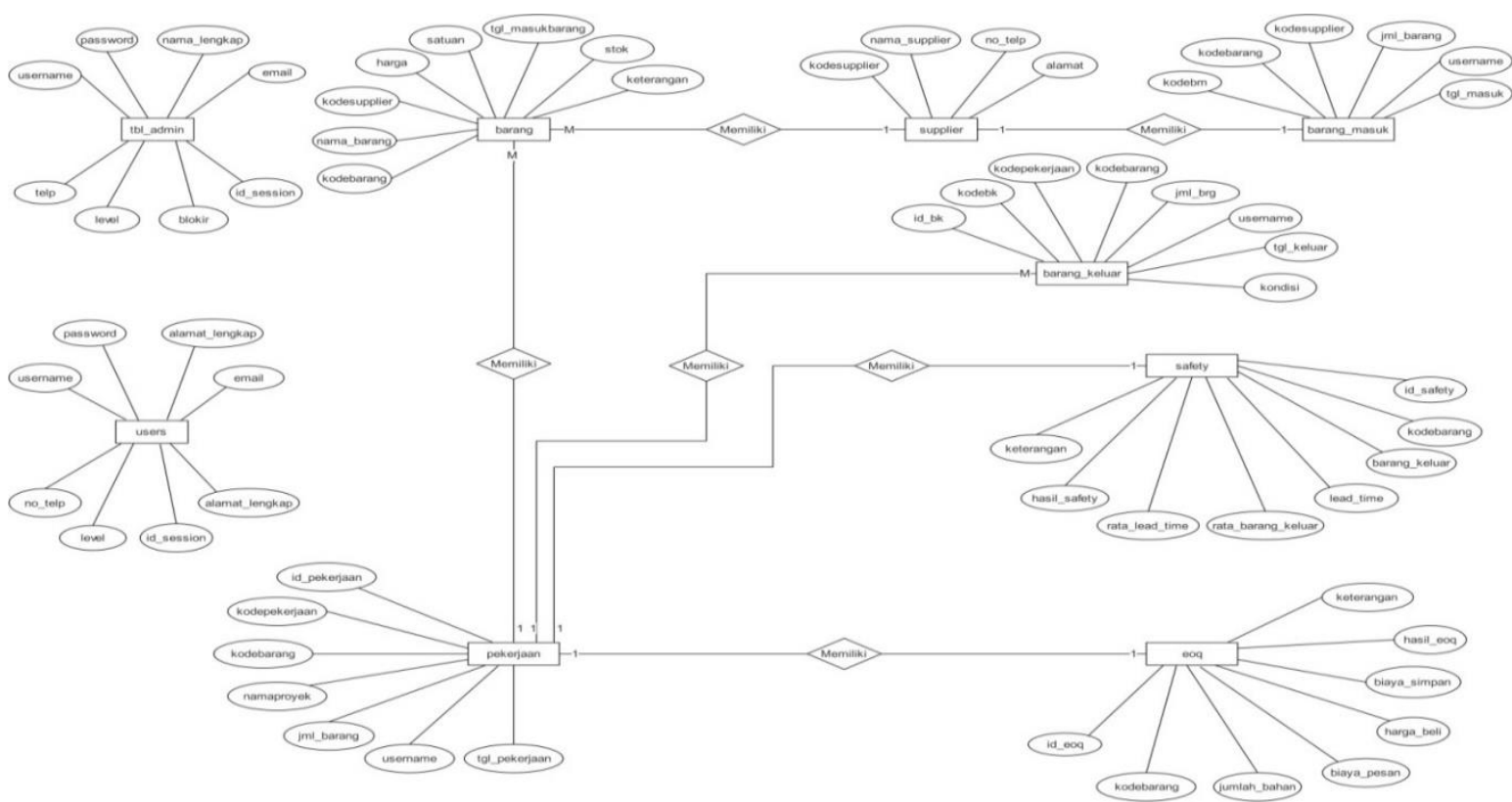

Gambar 4. Entity Relationship Diagram (ERD)

\subsection{Perancangan Desain Sistem}

1. Halaman Login Admin, Direktur dan Gudang

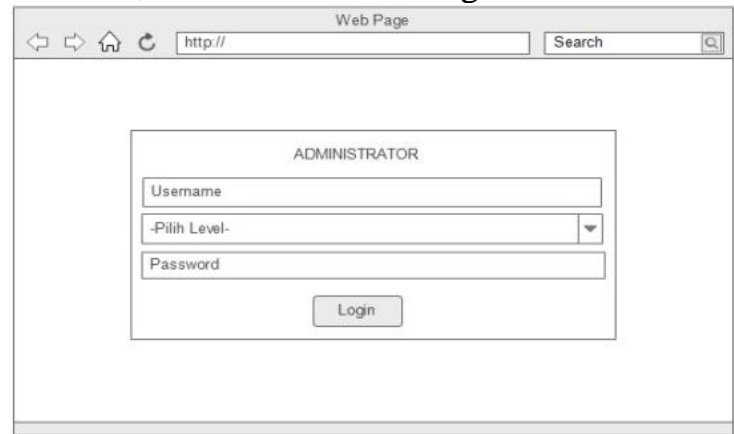

Gambar 5. Halaman Login Admin, Direktur dan Gudang

2. Halaman Beranda Admin

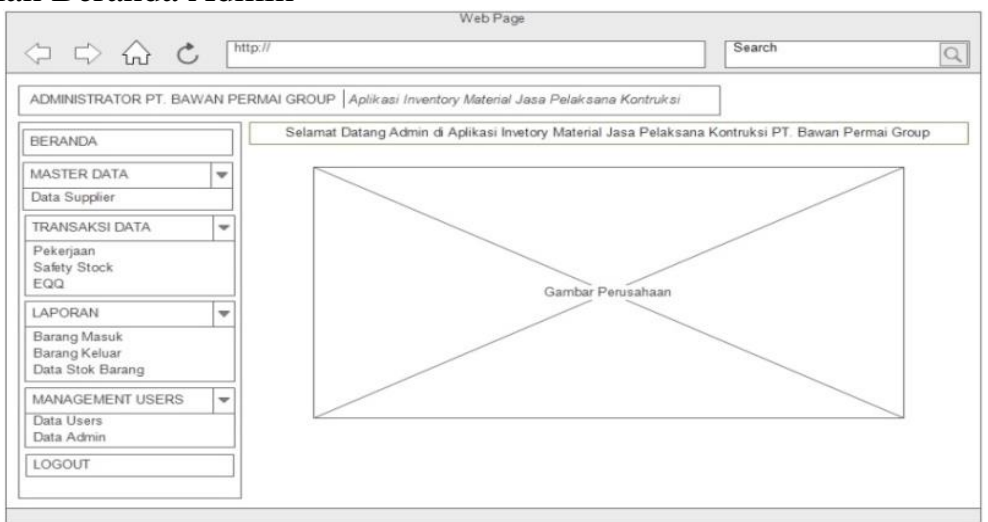

Gambar 6. Halaman Beranda Admin

3. Halaman Beranda Direktur 


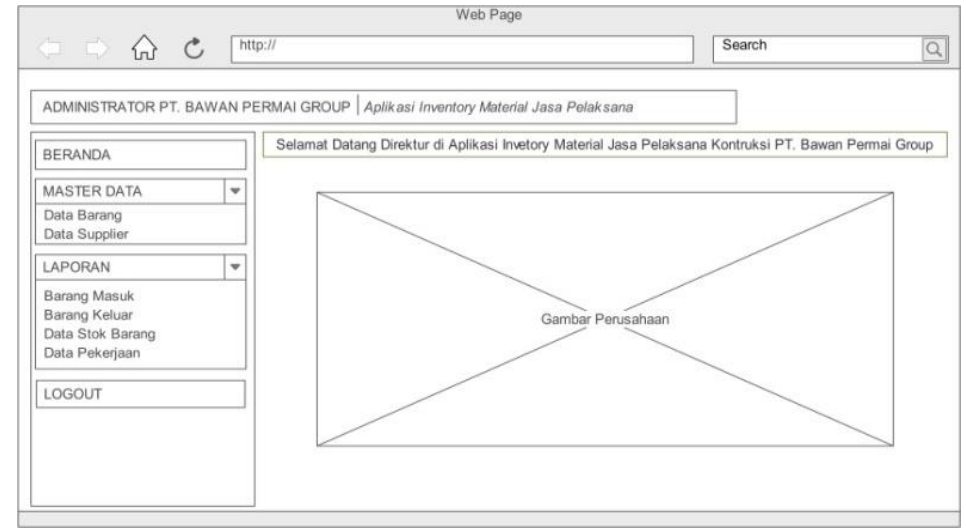

Gambar 7. Halaman Beranda Direktur

4. Halaman Beranda Gudang

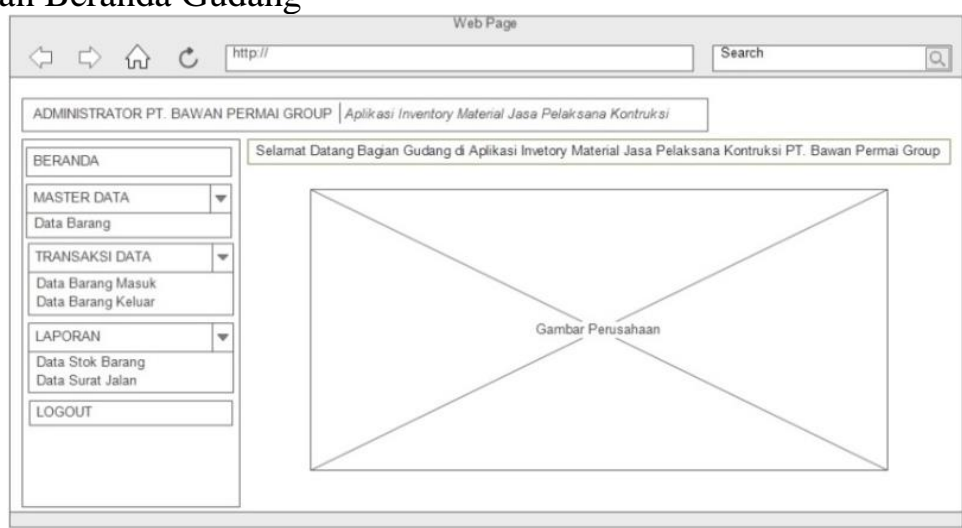

Gambar 8. Halaman Beranda Gudang

\subsection{Hasil Tampilan Sistem}

1. Tampilan Halaman Login Admin, Direktur dan Gudang

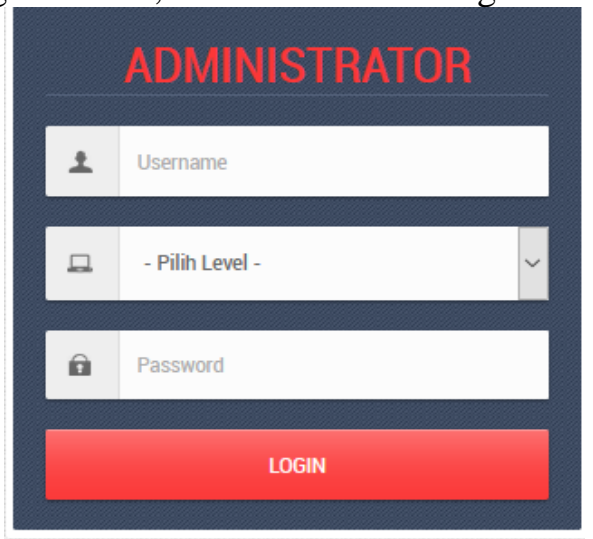

Gambar 9. Tampilan Halaman Login Admin, Direktur dan Gudang

2. Tampilan Halaman Beranda Admin 


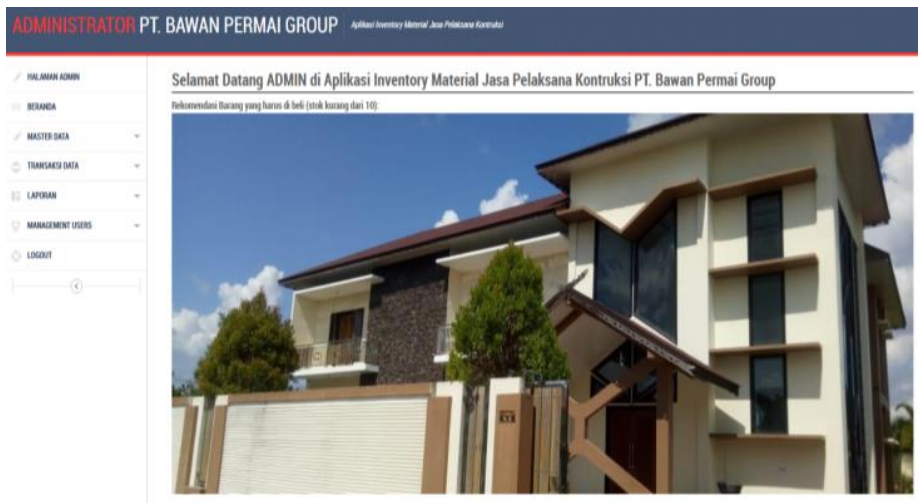

Gambar 10. Tampilan Halaman Beranda Admin

3. Tampilan Halaman Beranda Direktur

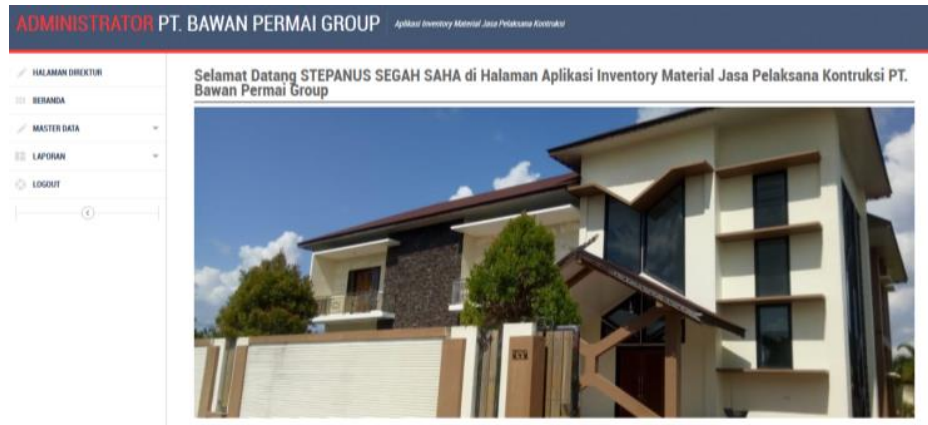

Gambar 11. Tampilan Halaman Beranda Direktur

4. Tampilan Halaman Beranda Gudang

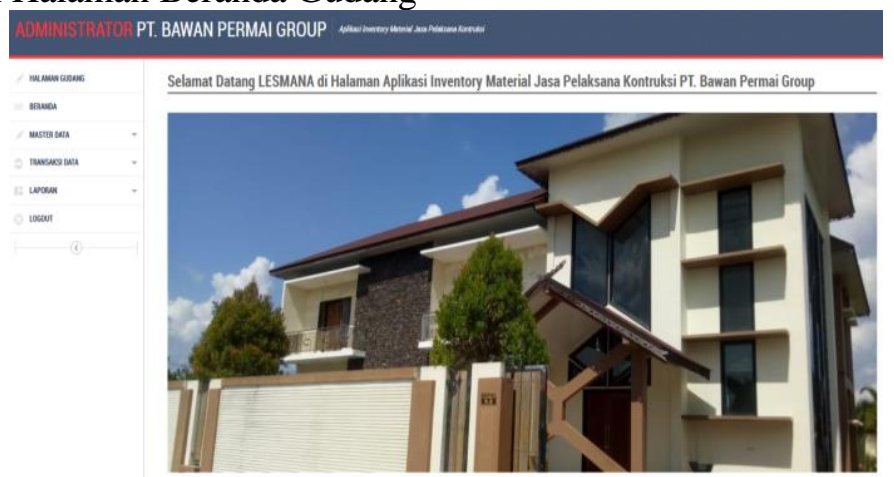

Gambar 12. Tampilan Halaman Beranda Gudang

\section{KESIMPULAN}

Berdasarkan hasil penelitian yang telah dilakukan maka dapat diambil kesimpulan, yaitu dalam merancang dan membangun website ini menggunakan metodologi pengembangan perangkat lunak Waterfall Menurut Summerville tahun 2011, yang memiliki tahapan yaitu Requirements Definition yang dilakukan dengan pembuatan Flowchart sistem lama dan sistem baru. System and Software Design dilakukan pembuatan Data Flow Diagram (DFD) dan Entity Relationship Diagram (ERD). Implementation and Unit Testing dilakukan realisasi sistem pada tahap sebelumnya ke dalam bahasa pemrograman PHP dan basis data MySQL. Integration and System Testing dilakukan pengujian kembali dengan menggunakan Blackbox Testing. Dari hasil pengujian ini dapat disimpulkan bahwa Website ini dapat berjalan sesuai dengan fungsinya. Dengan adanya Aplikasi Inventory Material Jasa Pelaksana Kontruksi PT. Bawan Permai ini 
mempermudah staff atau pegawai dalam mengelola dan mendata persediaan serta mempermudah pengontrolan bagi pimpinan perusahaan.

\section{DAFTAR PUSTAKA}

[1] Abdul, Kadir, Dasar Pemrograman WEB Dinamis Menggunakan PHP. Yogyakarta : Penerbit Andi, 2011.

[2] Ardhana, Kusuma YM. Project PHP \& MysSQL Membuat Website Buku Digital. Jasakom, 2014.

[3] Bahra Al. Analisis dan Desain Sistem Informasi. Yogyakarta : Graha Ilmu, 2013.

[4] Amsyah, Zulkifli Drs. MLS. Website Profil. Jakarta : Gramedia Pustaka Utama Fatta, 2011.

[5] Al, Hanif, Analisis \& Perancangan Website. Yogyakarta : Andi, 2013.

[6] Assauri, sofjan, Manajemen Operasi Produksi Pencapaian Sasaran Organisasi Berkesinambungan. Jakarta : PT. Raja Grafindo Persada, 2016.

[7] Sommerville, Ian, Software Engineering (Rekayasa Perangkat Lunak). Jakarta: Erlangga, 2011.

[8] Abi Abdurahim dan Leni Fitriani, "Rancang Bangun Aplikasi Inventory Sayuran Berbasis Desktop di Perusahaan CV. Garut Power", 2016.

[9] Arizal dan Anita Qoiriah "Sistem Informasi Inventory Control Pada Perusahaan Industri Gas di PT. XYZ’, 2014.

[10] Widiatry, W. \& Sari, N. N. K., (2019). Rancang Bangun Website untuk Memeriksa Plagiat E-Journal Fakultas Kedokteran Universitas Palangka Raya. Jurnal CoreIT 5(2), 36-43.

[11] Sari, N. N. K., Widiatry, W., \& Chitayae, N. (2018). Sistem Pendukung Keputusan untuk Seleksi Penerima Beasiswa BBP-PPA dengan Metode TOPSIS berbasis Web. Anterior Jurnal, 18(1), 86-91.

[12] Widiatry, W. \& Nugraha, A. (2018). Rancang Bangun Website E-Learning Sman 1 Palangka Raya. Jurnal Teknologi Informasi, 12(1), 57-62.

[13] Widiatry, W. (2020). Pengembangan Aplikasi Kartu Rencana Studi Online Pada Jurusan Pendidikan Luar Sekolah Universitas Palangka Raya. Jurnal Teknologi Informasi, 14(1), 83-93.

[14] Sari, N. N. K., Widiatry, W., \& Putra, P. B. A. A. (2020). Sistem Informasi Kepegawaian UPT Kesatuan Pengelolaan Hutan Produksi Kapuas Tengah UNIT XI. Jurnal Informatika, 7 (2), 183-191. 